\title{
Individually tracked geese follow peaks of temperature acceleration during spring migration
}

\author{
Rien E. van Wijk, Andrea Kölzsch, Helmut Kruckenberg, Barwolt S. Ebbinge, \\ Gerhard J. D. M. Müskens and Bart A. Nolet
}

R. E. van Wijk, A. Kölzsch (a.koelzsch@nioo.knaw.nl) and B. A. Nolet, Project Group Movement Ecology, Netherlands Inst. of Ecology (NIOO-KNAW), Droevendaalsesteeg 10, NL-6708PB Wageningen, the Netherlands and, Dept of Animal Ecology, Netherlands Inst. for Ecology (NIOO-KNAW), the Netherlands. - H. Kruckenberg, European White-Fronted Goose Research Programme, Germany. - G. J. D. M. Müskens and B. S. Ebbinge, Alterra Wageningen-UR, Team Molecular Ecology, Ecotoxicology and Wildlife Management, the Netherlands.

\begin{abstract}
Many migratory herbivores seem to follow the flush of plant growth during migration in order to acquire the most nutrient-rich plants. This has also been hypothesized for arctic-breeding geese, but so far no test of this so-called green wave hypothesis has been performed at the individual level. During four years, a total of 30 greater white-fronted geese Anser albifrons albifrons was tracked using GPS transmitters, of which 13 yielded complete spring migration tracks. From those birds we defined stopover sites and related the date of arrival at each of these stopovers to temperature sum (growing degree days, GDD), snow cover, accumulated photoperiod and latitude. We found that geese arrived at spring stopovers close to the peak in GDD jerk; the 'jerk' is the third derivative, or the rate of change in acceleration, and GDD jerk maxima therefore represent the highest acceleration of daily temperature per site. Day of snow melt also correlated well with the observed arrival of the geese. Factors not closely related to onset of spring, i.e. accumulated photoperiod and latitude, yielded poorer fits. A comparison with published data revealed that the GDD jerk occurs 1-2 weeks earlier than the onset of spring derived from NDVI, and probably represents the very start of spring growth. Our data therefore suggest that white-fronted geese track the front of the green wave in spring.
\end{abstract}

Many animals migrate twice a year between a survival and a reproduction habitat. In order to reproduce successfully, they must migrate at the right time, because both arriving too early or too late in the reproduction habitat often incurs a hefty penalty (Drent et al. 2003). Yet, little is known about the cues and decision rules that migrants use to time their migration. Photoperiod has been identified as a cue to prepare for migration in almost all migratory taxa (Bauer et al. 2011), which is not surprising as migration is often associated with seasonality, and photoperiod is a reliable indicator of time of the year. Additionally, photoperiod may relate to the phenology of resources. Plant growth is also frequently associated with temperature and rainfall (Mueller et al. 2008, Sherrill-Mix et al. 2008, Holdo et al. 2009), and because herbivores often prefer the new growth (Sawyer and Kauffman 2011), these factors might also serve as cues to time their migration. Alternatively, herbivores might follow the flush of growth directly.

For herbivorous migrants like geese, Drent et al. (1978) hypothesized that their 'movements are dictated to a large extent by changes in the relative profitability of the various food species'. Indeed, experiments have demonstrated that geese prefer to feed on grasses of higher nutritional value and digestibility (Bos et al. 2005, Stahl et al. 2006, van Liere et al.
2009). Thus, during spring migration geese might follow a climatological gradient and feed on the flush of nutrient rich grass along the way (Owen 1980). This concept was termed the green wave hypothesis (Schwartz 1998, van der Graaf et al. 2006).

Ideally, one would continuously monitor the quantity and quality of forage plants on the ground along the entire migratory route, and express this for instance as nutrient biomass $\left(\mathrm{g} \mathrm{N} \mathrm{m}^{-2}\right)$, combining the food quantity $\left(\mathrm{g} \mathrm{m}^{-2}\right)$ and quality of forage plants (\%N) (van der Graaf et al. 2006). Given that such measurements are logistically impossible, several proxies have been used to characterize a flush of growth or the onset of spring, also in relation to the timing of avian migration. Hüppop and Hüppop (2003) showed that the North Atlantic Oscillation (NAO; Lappalainen et al. 2008) was correlated with spring arrival dates in several bird species in Europe, but this was not the case in long-distance migratory birds in North America (Marra et al. 2005). Because of their slow growth, plants appearing from under the melting snow are of high quality (Fox et al. 1991), and hence day of snow melt may be another valid measure for the onset of spring; this measure is however only of use in areas where snow might delay the onset of growth. Another predictor, examined by Tombre et al. (2008), is the normalized difference 
vegetation index (NDVI). It is derived from satellite imagery and is therefore of high resolution, less sensitive to differences in observation effort and can be applied to large regions. However, NDVI data are (bi)weekly averages resulting in a loss of temporal detail critical to interpreting the timing of migration.

Another good proxy may be growing degree days (GDD), i.e. the sum of mean daily temperatures above a certain temperature threshold, as has traditionally been used in phenology studies (Wang 1960). Using a threshold of $0^{\circ} \mathrm{C}$ and the starting date 1 January, van Eerden et al. (2005) showed that the day at which the GDD reached $180^{\circ} \mathrm{C}$ corresponded well with the onset of spring growth of graminoids, the major food source of staging geese. Indeed, the green wave hypothesis was supported by the match between goose migration volume and plant phenology or plant growth inferred from accumulated temperature (van der Graaf et al. 2006, Duriez et al. 2009). The green wave hypothesis has however never been tested at the individual level. The successful application of miniature GPS-devices to track individual geese (Kruckenberg et al. 2008a) finally enables us to do so.

In this study we focused on individual greater whitefronted geese Anser albifrons albifrons, hereafter 'whitefronted geese', that migrate from their wintering grounds in the Netherlands to their breeding grounds in the European Russian and west-Siberian arctic (Kruckenberg et al. 2008b). The migration of white-fronted geese is an ideal system to test the green wave hypothesis and assess the timing of migratory movements in relation to measures that may indicate spring growth. Like many other goose species, white-fronted geese are known to be capital breeders, meaning that energy and nutrient stores required for breeding must be acquired en route and 'flown-in' to the breeding site (Spaans et al. 1999). Geese like white-fronted geese are therefore not only forced to arrive early at their breeding sites, but also to forage efficiently during migration. Unlike some other goose species, white-fronted geese show a predominantly continental migration route, and hence the timing of their migration is not affected by the need to fly over stretches of sea, which may constrain the ability to follow the flush of growth. And unlike many other goose species, white-fronted geese migrate over a broad front from their wintering to their breeding grounds, the most southern migration routes pass through the Ukraine, whereas the most northern routes go through the Baltic states. Yet, the onset of spring is related to geographical location, with spring starting later, but advancing faster, in the Ukraine and European Russia than in Poland and the Baltic states (Schwartz et al. 2006). If migratory movements are related to the onset of spring, geese should follow the flush of new growth along the particular route they take, with geese following the southern route expected to catch-up to birds following the northern route at some point during their migration.

We tested whether the timing of spring migration of individual, GPS-tagged white-fronted geese could be predicted more accurately by variables related to the green wave (temperature sum in the form of GDD or its derivatives, and date of snow melt) than by variables related to other cues (accumulated photoperiod or latitude).

\section{Methods}

\section{GPS data}

In 2006, 2007 and 2008 a total of 30 male adult whitefronted geese were equipped with a GPS/PTT-transmitter (Solar GPS 100 PTT $45 \mathrm{~g}$ ), after being captured on their wintering grounds in the Netherlands. The transmitter was attached on their back with a harness (Fig. 1A; Kruckenberg et al. 2008a). We only tracked male birds, because they are heavier than females and are therefore expected to be better capable of carrying a transmitter without impediment. Furthermore, paired birds travel together during migration (within larger groups), thus the data of the males is also representative for females. After catching, paired birds have been observed together, thus their bond prevails beyond this as well as other kinds of disturbance (Owen 1980). The attached transmitters were programmed to send the recorded GPS locations to ARGOS satellites every other day. The number of data points per day varied from one to ten, averaging five per day. Data gaps of up to two weeks were seen in a small number of birds $(<5)$, however, these gaps predominantly occurred on the wintering grounds (for details on tracks see $<$ www.blessgans.de $>$ ).

We selected the GPS tracks of those geese that included at least one complete spring migration from the wintering to the breeding grounds, resulting in 13 tracks in total ( $\mathrm{n}=1$ in 2006, $\mathrm{n}=7$ in 2007 and $\mathrm{n}=5$ in 2008). Of the birds that did not yield such tracks, five were shot, four had tags which failed and eight had tags which stopped signalling for unknown reasons (the birds were either shot/predated or tags failed) before the birds reached their breeding grounds. In the two cases where we had data of one individual for more than one complete spring migration, only the track from the first year was used for the inter-individual analysis. This resulted in a dataset of over 15000 different positions, with approximately 1000 different positions per bird per spring. In addition, we conducted intra-individual (i.e. betweenyear) comparisons for the two birds that were tracked for more than one spring (no. 79698 in 2008 and 2009, and no. 72413 in 2007, 2008 and 2009).

\section{Delineation of stopovers}

During spring migration white-fronted geese use several stopover sites along the way. We determined the location of each of these stopovers by a two-step process. We first identified clusters of successive positions where an individual bird did not displace more than $30 \mathrm{~km}$ between pairs of positions. This displacement threshold is in line with maximum distances between resting and foraging grounds at wintering sites (Ebbinge unpubl.). Those clusters, where the bird stayed for at least $48 \mathrm{~h}$, i.e. the time needed to settle and refuel (Drent et al. 2006), were defined as stopover sites. To be conservative, we considered a return to the cluster within $8 \mathrm{~h}$ after a detour of $>30 \mathrm{~km}$ to be part of the same stopover. When the bird undertook more than one such 'detour' flight it was considered to have left that particular stopover site. The stopover site location was defined as the centre of all locations of the respective cluster, calculated as the average of longitudes and latitudes. 


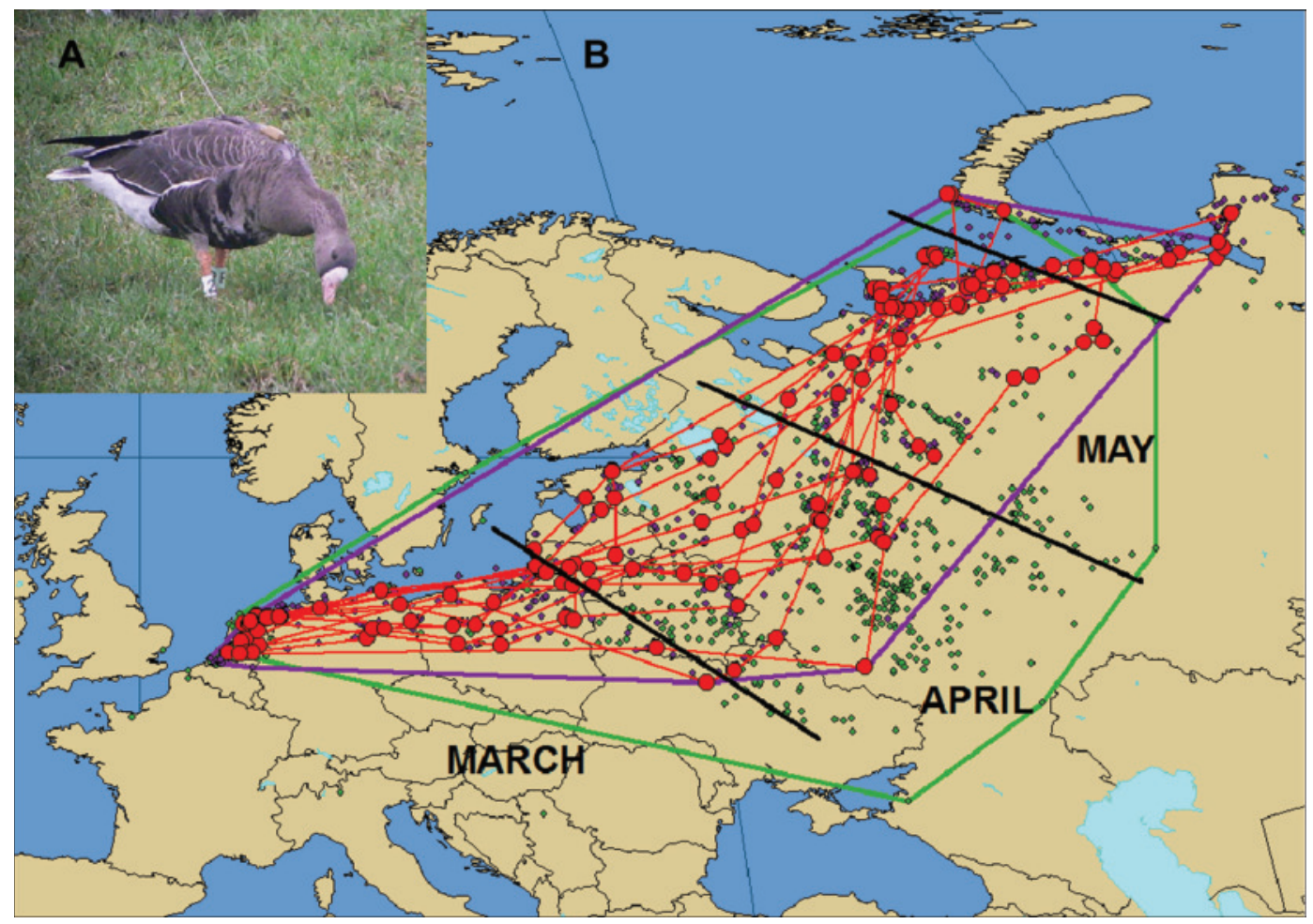

Figure 1. The study species and their migration routes. (A) A greater white-fronted goose (Anser albifrons albifrons) equipped with a GPS device (picture by O. Kwak). (B) Overview of the migration routes of the white-fronted geese in this study. Red dots represent wintering sites (located in the Netherlands), stopover sites and breeding grounds (last point of a track). Approximate timing is indicated. Positions of used GPS data (purple points) and metal ring recoveries (green points) are given and its ranges ( $95 \%$ minimum convex polygon) are outlined (GPS data: purple line, ring recoveries: green line).

\section{Predictive variables}

We used the following four measures to calculate predicted arrival dates for the individual birds at each stopover site, and to compare those with observed arrival dates: growing degree days (GDD) and derivatives thereof, day of snow melt, accumulated day length and latitude.

\section{Growing degree days (GDD)}

To calculate the GDD for all stopover sites, we used 1) an embedded, interpolated temperature dataset of the European Climate Assessment (ECA; Haylock et al. 2008), or if such data were not available, 2) data of weather stations located within a $75 \mathrm{~km}$ radius of the stopover site (preferably at the same latitude). We acquired, in order of preference, weather station data from the NOAA (National Oceanic and Atmospheric Administration), the Russian Weather Archive $(<$ www.meteo.infospace.ru $>)$ and from MetOffice $(<$ www. metoffice.gov.uk $>$ ) obtained via the Russian weather site 'RP5' (< www.rp5.ru >). We obtained the mean daily temperatures, $\mathrm{T}_{\mathrm{AVG}}^{\mathrm{k}}$, for all stopover sites and respective years for $\mathrm{k}=1,2, \ldots, 365$, i.e. 1 January until 31 December.

Because of the wide geographical range of our study we derived a varying threshold temperature for plant growth $\mathrm{T}_{\text {BASE }} \cdot \mathrm{T}_{\text {BASE }}$ was estimated to vary from $0^{\circ} \mathrm{C}$ (Lantinga $1985)$ in the Netherlands $\left(52^{\circ} \mathrm{N}\right.$, Lantinga 1985$)$ to $-5^{\circ} \mathrm{C}$ in northern Russia $\left(72^{\circ} \mathrm{N}\right.$, Botta et al. 2000). Because the average annual temperature decreases with increasing latitude in a linear fashion (i.e. Reynolds 1981), we calculated $\mathrm{T}_{\text {BASE }}$ at a given latitude as: $\mathrm{T}_{\mathrm{BASE}}=-0.25 \times$ latitude +13 (parameters derived from a linear regression through the given end points). For each location and day of the year $\mathrm{T}_{\text {BASE }}$ was then subtracted from $\mathrm{Tk}_{\mathrm{AVG}}$ to calculate growing degree units of day $k, G^{k}=T^{k}{ }_{A V G}-T_{B A S E}$. If $T^{k}{ }_{A V G}<T_{B A S E}$, it was set to $\mathrm{T}_{\mathrm{BASE}}$, so GDUk would be 0 . The GDD of a certain Julian day $\mathrm{k}, \mathrm{GDD}^{\mathrm{k}}$ is the accumulation of growing degree units from 1 January onwards:

$G D D^{k}=\sum_{i=1}^{k} G D U^{i}$

As proposed earlier (Lantinga 1985, van Eerden et al. 2005), the day at which GDD reached $180^{\circ} \mathrm{C}$ was used as a predictor for spring start. We analysed the GPS tracks to verify which particular GDD value yielded the most parsimonious model explaining the moment of goose arrival at stopover sites. Further, we related the tracks to the third derivative (in physics literature called 'jerk') of the GDD. The GDD jerk is the rate of change in acceleration of GDD, i.e. the acceleration of temperature, which is a proxy for the onset of spring (Fitzjarrald et al. 2001). The GDD jerk was derived from a fitted sigmoid through the function of GDDk (Fig. 2).

\section{Day of snow melt}

The day of snow melt was defined using snow cover data from the National Oceanic and Atmospheric Administration (NOAA), recorded using a combination of remote sensing 

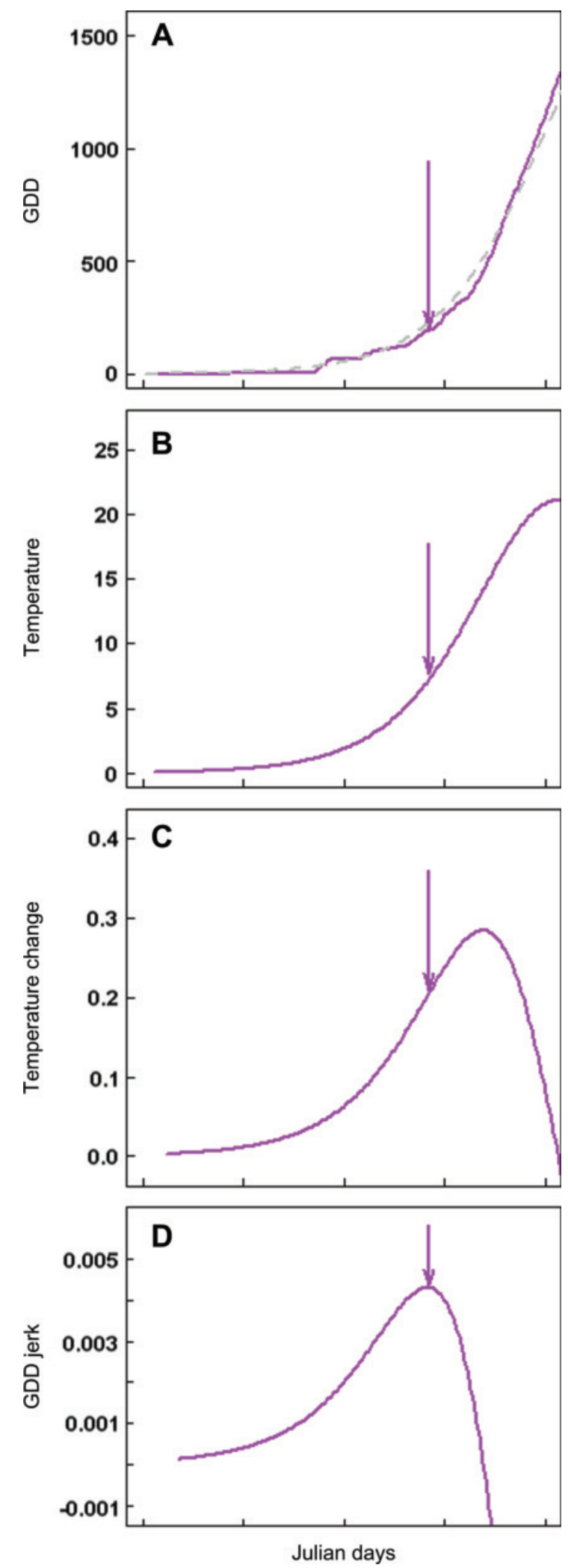

Figure 2. Illustration of the derivation of the GDD jerk in respect to different measures of temperature. The arrow indicates the arrival of bird no. 72364 at a stopover site near the city of Nes' in Russia. (A) the GDD (temperature sum) and its sigmoid fit, (B) the first derivative of the GDD fit, i.e. temperature, $(\mathrm{C})$ the second derivative of the GDD fit, i.e. the change of temperature and (D) the third derivative of the GDD fit, i.e. the GDD 'jerk' or the acceleration of temperature. infrared and microwave sensors. It contains presence/absence data of snow according to a coverage threshold at a $4 \times 4 \mathrm{~km}$ resolution. The day of snow melt was defined as the latest Julian date for which no snow cover was reported in the respective region immediately following a period of at least seven days of continuous snow cover. We only considered the effect of snow melt at stopover sites with at least three weeks of continuous snow cover in January in order to eliminate areas where snow cover is too sporadic to be related to the onset of growth (e.g. the Netherlands).

\section{Accumulated photoperiod}

In order to calculate the predicted arrival of a bird at stopovers based on accumulated day length, each individual migration track was initiated at the time the respective bird undertook its first movement out of the wintering area. To those initial times we added by alternation flight durations (three days, based on the GPS data) and stopover durations. The stopover duration for each stopover site was calculated as the time a bird had to stay to accumulate $118 \mathrm{~h}$ of daylight, i.e. photoperiod (period between sunrise and sunset), $118 \mathrm{~h}$ being the median summed photoperiod over all geese and stopovers.

\section{Latitude}

We performed a linear regression of observed arrival times on latitudes of the stopovers. The parameters estimated by this regression were then used to calculate predicted arrival dates at the respective stopover sites according to their latitude.

\section{Comparison of predictors}

In order to compare how well each variable predicted the timing of spring migration, plots were generated of the observed arrival dates $y_{i}$ at the different stopover sites $i(i=1,2, \ldots, n)$ versus the predicted arrival dates $x_{i}$. We statistically compared predicted and observed arrival dates using the so-called 'root mean square deviation' (Kobayashi and Salam 2000)

$$
\mathrm{RMSD}=\sqrt{\frac{1}{n} \sum_{i=1}^{n}\left(x_{i}-y_{i}\right)^{2}}
$$

We defined RMSD values $<10$ days as a good fit, 10-15 days as moderate and $>15$ days as poor based on Duriez et al. (2009). RMSD values were calculated for each spring track (including those from the same individuals used in the between-year comparison).

\section{Representativeness of tagged birds}

To investigate whether the tracks of the satellite tagged birds were representative for the considered population, we compared them with recoveries of white-fronted geese ringed with metal or colour rings in the Netherlands in the years 2000, 2001 and 2002. First, we examined the spatial representativeness by comparison with metal ring recoveries (by hunters), because their spatial distribution is less biased than that of colour ring resightings. We determined the $95 \%$ minimum convex polygon of GPS positions and of the metal ring recoveries during spring, and overlaid its areas to determine the overlap. Second, we examined the temporal representativeness by comparison with colour ring resightings that 
are entered in an online database and therefore provide more reliable observation dates than hunting data. We chose ring resighting positions closer than $60 \mathrm{~km}$ to our stopover sites, and compared the ring observation dates with the arrival dates of the tagged geese.

All statistical analyses were conducted with $\mathrm{R}$ (R Development Core Team 2010). To calculate the minimum convex polygons we used the HRT Tools within ArcGIS ver. 9.3.

\section{Results}

\section{Stopover determination}

In total, 121 stopover sites were defined (Fig. 1B), ranging from 5 to 13 per bird, with an average of 10 . Distances between stopover sites varied from 47 to $1741 \mathrm{~km}$, averaging $404 \mathrm{~km}$ $(\mathrm{SD}=331 \mathrm{~km})$. Stopovers were scattered over a broad spatial range, with a northern route going through Poland and the Baltic states, and a southern route through the Ukraine and districts around Moscow in Russia. Intermediate routes passed through Belarus. Regardless of which route a goose took, all individuals arrived around the same time in Arkhangelsk Oblast in northern Russia, with southern birds catching-up to the more northerly migrants before entering the breeding grounds. From there, most birds went on directly to their breeding grounds on Kolguyev or in the Pechora Delta, others continued to Novaya Semlya or as far as Taimyr.

\section{Spring migration timing}

The annual pattern of GDDs for each stopover were well described by sigmoid functions (logistic regressions, $\mathrm{r}^{2}>0.99$; Fig. 2A, 3A). Spring warming started later, and GDD maxima differed, along the geographical gradient from the wintering to the breeding range of the geese.

Contrary to our expectation, the birds arrived at stopover sites at varying GDD values (Fig. 3B). For example, arrivals at the last stopover and at the breeding site were at days with GDDs less than those at earlier stopovers. Maxima of GDD jerks, however, showed a striking coincidence with bird arrivals (Fig. 3C), especially when the peaks were very sharp. There was a good fit between observed arrival dates at stopover sites and arrival dates predicted using the GDD jerk (Fig. 4B, Table 1, the complete list of RMSD values is in Appendix 1). Similarly, arrival dates predicted from day of snow melt ('snow cover') fitted observed arrival dates quite well (Fig. 4C). The GDD of $180^{\circ} \mathrm{C}$ produced only moderate fits (Fig. 4A, Table 1), with birds generally arriving later than predicted. We tried which GDD value fit the data best, and found a GDD of $299^{\circ} \mathrm{C}$ (RMSD of 13.40 , cf. Table 1$)$. This value gives a slightly better fit than the GDD jerk, but cannot be generalised, as it is not independent from our tracking data. Predicted arrival dates based on accumulated photoperiod and latitude both showed worse fits with the observed arrival dates (Fig. 4D, E, Table 1). The fit of latitude nicely shows that one bird (no. 62350) first migrated south and later north, causing a hump in the graph.

The two birds that were tracked for more than one spring followed very similar migration routes in the subsequent
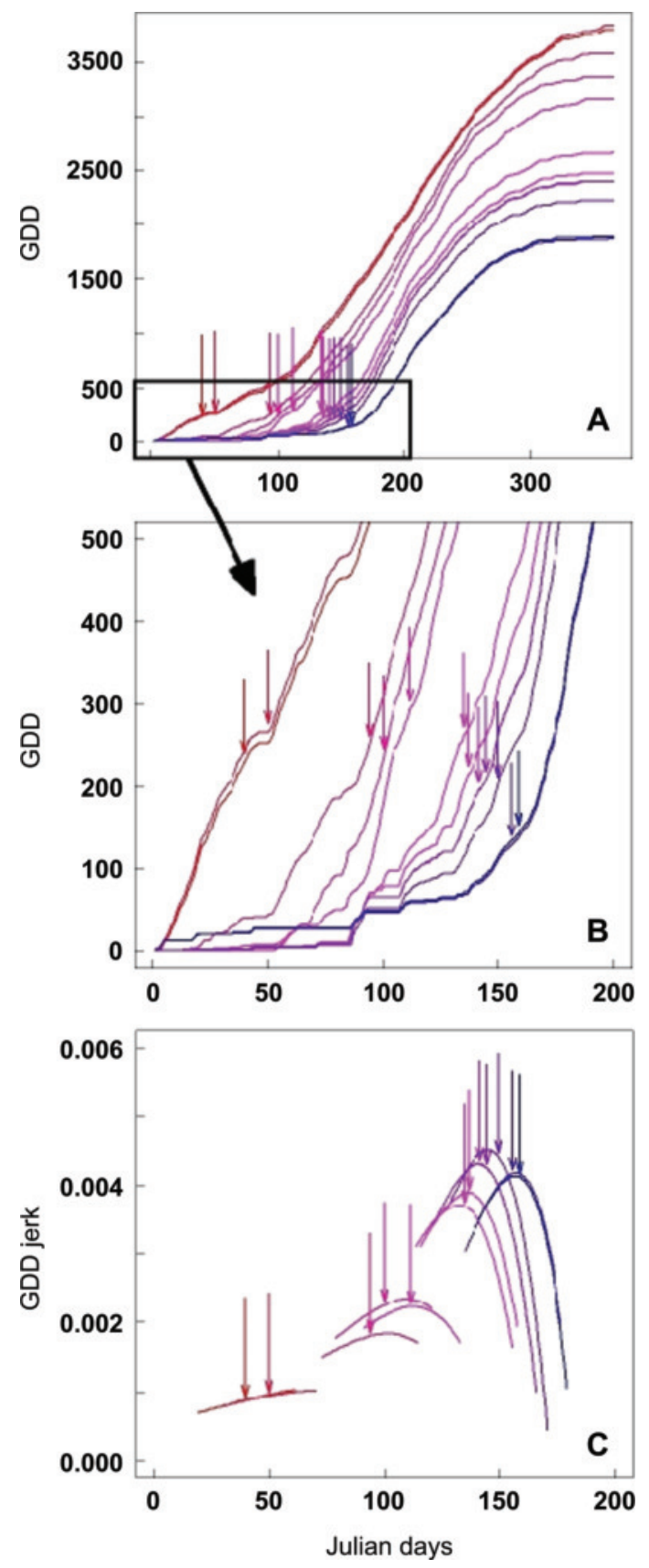

Figure 3. Illustration of the GDD and GDD jerk for all stopovers of bird no. 79698 in 2008 (GDD = growing degree days). Arrows indicate the observed arrival and colours represent the different stopovers (red 'the Netherlands', pink 'Belarus', purple 'western Russia', blue 'northern Russia'). (A) Progression of GDD values at each stopover site over one year's spring migration, (B) GDD zoomed in to the spring migration period, (C) the GDD jerks for the respective stopover sites three weeks before and after the peak.

years, and the observed arrival dates fitted those predicted by GDD jerk generally well (Fig. 5).

\section{Representativeness of tagged birds}

The range of the satellite tagged data comprised $70.9 \%$ of the metal ring observations (Fig. 1), while vice versa the range of 

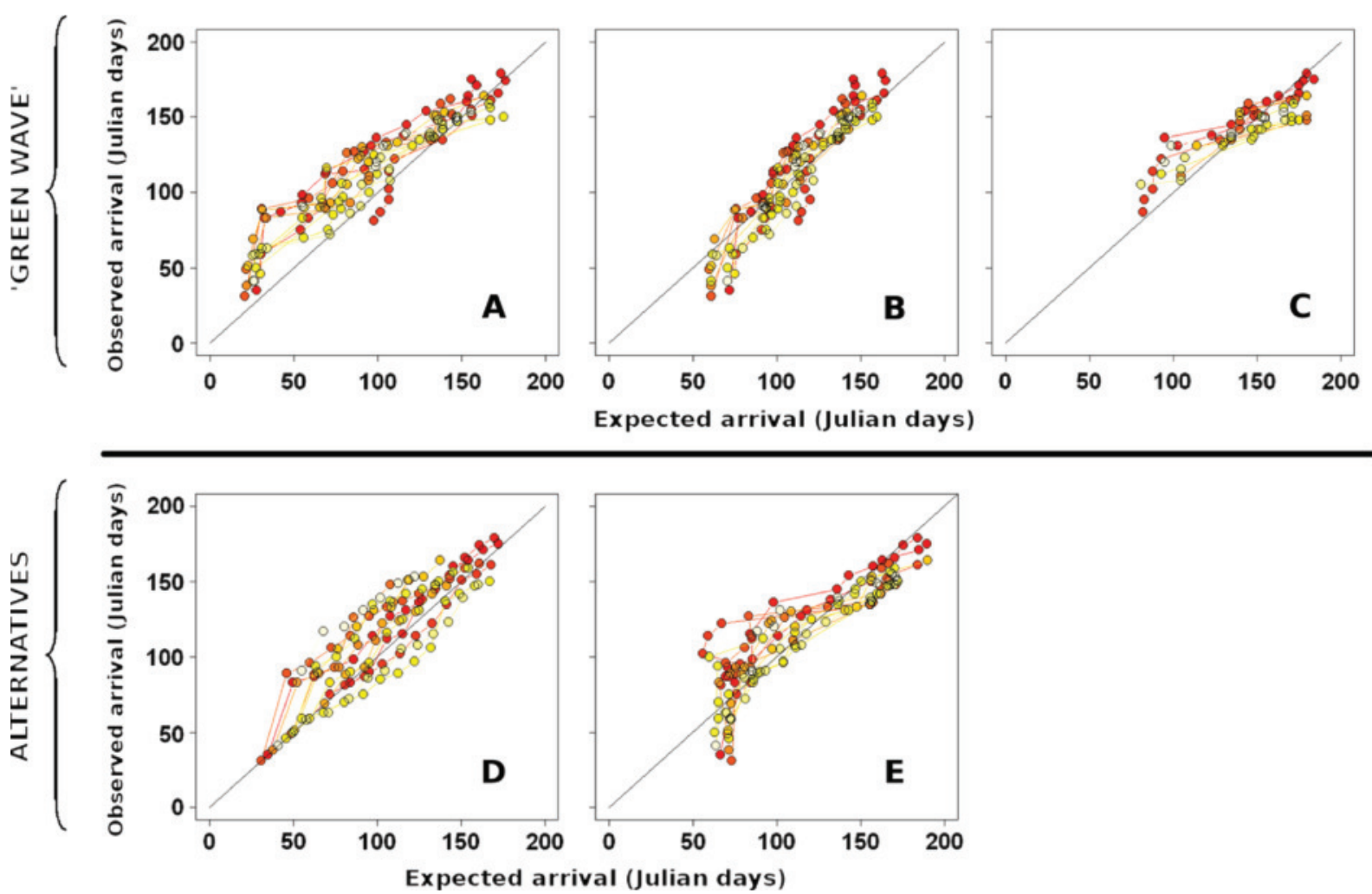

Figure 4. Observed vs expected arrival dates for measures predicting the geese' spring migration timing. Dots indicate stopover sites. Supporting the green wave hypothesis are (A) GDD $180^{\circ} \mathrm{C}$, (B) GDD jerk and (C) snow cover; alternative timing explanations are (D) accumulated photoperiod and (E) latitude. Colours show the breeding status of the birds: white is a successful breeder, red a non-breeder. Colours in between represent the intervening gradient in breeding status.

the metal ring recoveries comprised $88.9 \%$ of the range of our satellite tagged birds. Regarding time, the arrivals of the tagged birds corresponded well with the resighting dates of colour ringed geese in the same area, being on average only one day earlier $(\mathrm{SD}=3.1$ days). Average differences of up to four days appeared only at low sample sizes (Table 2).

\section{Discussion}

Our analyses strongly suggest that individual white-fronted geese follow the peaks in acceleration of temperature during their spring migration. Their arrival at stopover sites coincided well with specific measures of growing degree days, snow cover disappearance and, best of all, with the GDD jerk (i.e. the third derivative of the GDD). Alternative explanations for

Table 1. Overall root mean square deviation (RMSD) values for arrival dates at the stopovers of 13 individual white-fronted geese for the different measures used to predict the timing of spring migration $(\mathrm{GDD}=$ growing degree days).

\begin{tabular}{lc}
\hline Explanatory variable & RMSD \\
\hline GDD jerk & 13.63 \\
Snow cover & 15.24 \\
Latitude & 18.54 \\
Photoperiod & 19.59 \\
GDD $180^{\circ} \mathrm{C}$ & 23.90 \\
\hline
\end{tabular}

the timing of spring migration, accumulated photoperiod and latitude, clearly yielded poorer predictions of the arrivals at stopovers.

Greening up or the onset of spring is strongly related to temperature (Fitzjarrald et al. 2001, Suzuki et al. 2003). The GDD jerk is derived from temperature, but to draw general conclusions from this study specific comparisons between greening up and the GDD jerk have to be performed. Therefore, we compared the GDD jerk with an estimate of the onset of spring that was developed in a study on vegetation greening up throughout northern Asia using NDVI data (Suzuki et al. 2003). It has been shown that NDVI is a reliable predictor for vegetation availability and quality, and valid for application in population ecology studies (Hamel et al. 2009). We show that the peaks of the GDD jerk were consistently 1-2 weeks earlier than their predicted onset of spring date (Appendix 2). However, the NDVI data had been collected on a weekly basis, so our predictions fall within the time scale of the NDVI predictions, strongly suggesting that the GDD jerk is useful in describing the front of the green wave over vast regions.

In a model study by Fitzjarrald et al. (2001), it was found that not only temperature, but also relative humidity is of importance for green-up timing, especially in forests. They concluded that leaf emergence and transpiration may cause a feedback on temperature, hampering the acceleration of temperature increase after the first flush of green. This would fit the notion that at times of maximum GDD jerk, the first 


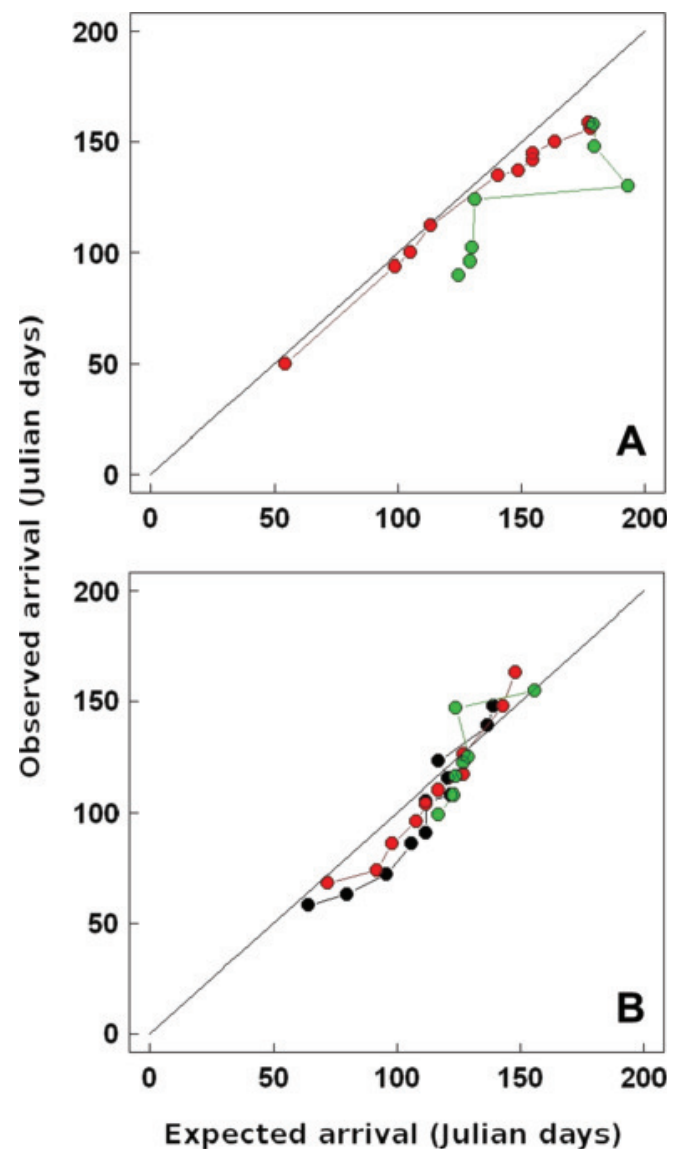

Figure 5. Observed vs by GDD jerk expected arrival dates for the different years (black 2007, red 2008 and green 2009) of (A) bird no. 79698 and (B) no. 72413 . No. 79698 was a breeder in 2008, but failed in 2009. No. 72413 bred in 2007 and 2009, but failed to breed in 2008 .

and most nutrient rich leaves and grasses sprout, with temperature increase slowing thereafter. In the same study by Fitzjarrald et al. (2001) it is stated that green-up times are strongly influenced by vegetation types and therefore similar NDVI values may indicate different green-up status according to geographical region. This is problematic when using NDVI as a predictor for the onset of spring. The GDD jerk, however, can be adapted, choosing for different base temperatures for growth, $\mathrm{T}_{\mathrm{BASE}}$, per region. Additionally, it is a relative measure, and therefore less dependent on vegetation type. Such vegetation type differences may not influence our analysis, because white-fronted geese only forage on similar types of habitat, grassland and cropland (Kruckenberg 2003).
Because white-fronted geese are known to be strict capital breeders (Spaans et al. 1999), it may be essential for them to follow the green wave during spring migration in order to acquire sufficient energy and nutrients for egg laying and incubation. Therefore, breeding success may be influenced by how well individual geese 'surf on the crest of the green wave' (van der Graaf et al. 2006). We correlated the timing of our birds to individual breeding status, because there seemed to be differences in how well they followed our predictions (Table 3). Birds were classified as either successful breeder $(n=3)$, late failed breeder $(n=1)$, early failed breeder $(n=7)$ or non-breeder $(n=2)$. The classification was based on small-scale movement patterns of the tracked male within the breeding area during summer and, if possible, on the basis of on-site observations $(n=3)$. We found that the quality of the fit of arrival dates predicted from the GDD jerk tended to vary in accordance with the bird's breeding status (logistic regression, $Z=-1.83, p=0.07$ ). It gave poorer fits for non-breeders and failed breeders than for successful breeders, suggesting the latter arrived closer to the optimal timing at most of the stopovers (Fig. 3B). No such difference in fit was apparent between birds following southern or northern routes. In addition, bird no. 79698 was ahead of the GDD jerk for the majority of his 2009 spring migration, a year in which he failed to breed, while in the other year he followed the GDD jerk closely and successfully bred (Fig. 5). Bird no. 72413 timed its migration close to the GDD jerk in all three analysed years and successfully raised chicks in two of the summers. The year that he failed, he arrived approximately ten days later at the breeding site than the other years. These indications strongly support the expectation that breeding status is related to how well individual geese follow the green wave. However, we cannot discern if birds failed to breed successfully because they did not time their migration well, or whether they were non-breeders (i.e. subadults or unmated), and therefore did not need to optimise their migration schedule as closely (Kruckenberg and Borbach-Jaene 2004). Moreover, birds that flew further east to Novaya Semlya or Taymir were mostly non-breeders, likely heading for moulting sites instead of breeding habitat (Kruckenberg et al. 2008a,b).

Our finding that birds arrived earlier at their breeding grounds than predicted by snow melt corresponds well with earlier studies. Geese appear to reserve the period of nutrient-rich grass on the breeding areas for when they are raising their young (van der Graaf et al. 2006). Therefore, they aim to initiate their nest as early as possible, when only few places are free of snow and thus when there is strong competition for good nesting sites. Many birds arrive before snow

Table 2. The first, last and average date (Julian day) colour-ringed geese were observed during spring migration in five different areas versus the first, last and average arrival dates of satellite-tagged geese in the same regions, i.e. no more than $60 \mathrm{~km}$ from its centre. For clear comparability differences in average arrival dates are given.

\begin{tabular}{|c|c|c|c|c|c|c|c|}
\hline \multirow[b]{2}{*}{ Location (lat, lon) } & \multicolumn{3}{|c|}{ Observed ringed geese } & \multicolumn{3}{|c|}{ Satellite-tagged geese } & \multirow{2}{*}{$\frac{\text { Difference }}{\text { Average }}$} \\
\hline & First & Last & Average & First & Last & Average & \\
\hline Szamocin $\left(53^{\circ} 05^{\prime}, 17^{\circ}\right)$ & 80 & 80 & $80(n=1)$ & 63 & 93 & $77(\mathrm{n}=3)$ & -3 \\
\hline Šilutè $\left(55^{\circ} 21^{\prime}, 21^{\circ} 18^{\prime}\right)$ & 83 & 99 & $90(\mathrm{n}=8)$ & 83 & 98 & $90(n=6)$ & 0 \\
\hline Šalčininkai $\left(54^{\circ} 28^{\prime}, 25^{\circ} 06^{\prime}\right)$ & 99 & 102 & $100(n=2)$ & 96 & 96 & $96(n=1)$ & -4 \\
\hline Lake Ladoga $\left(60^{\circ} 45^{\prime}, 32^{\circ}\right)$ & 115 & 139 & $125(n=6)$ & 125 & 131 & $128(n=3)$ & 3 \\
\hline
\end{tabular}


Table 3. Individual RMSD values of the observed arrival dates at stopover sites compared with the arrival dates predicted by the GDD jerk. Birds ordered according to breeding status: birds no. 79689 and no. 79696 were definitely non-breeders and no. 72413 and no. 79694 were definitely successful breeders. Note that worse fits only occur at the top end of the table, starting with the non-breeding birds.

\begin{tabular}{lr}
\hline Bird ID & RMSD \\
\hline 79689 & 18.35 \\
79696 & 16.38 \\
62350 & 16.45 \\
72364 & 15.26 \\
72416 & 11.97 \\
73052 & 10.75 \\
72417 & 10.11 \\
73053 & 8.89 \\
79695 & 13.53 \\
73054 & 10.91 \\
79698 & 7.73 \\
72413 & 13.96 \\
79694 & 13.49 \\
\hline
\end{tabular}

melt and feed on the stems of Carex aquatilis or Eriophorum angustifolium which they dig out from melting boggy soil (Budeau et al. 1991, Krechmar and Kondratyev 2006). However, to ensure that they do not deplete their fat reserves before breeding, and to avoid predation, birds should not arrive too early (Black et al. 2007, Ely et al. 2007). In conclusion, timing of arrival to the breeding areas is very complex, requires the careful balance of a number of factors, and cannot, therefore, be solely predicted by the green wave.

The alternative predictors for the timing of migration (accumulated photoperiod and latitude) performed worse than temperature-related measures, despite the fact that their derivation involved fitting parameters and data tuning. For example, the predictions based on accumulated photoperiod used the first departure date of the particular bird as a starting point, and flight duration was based on the data as well. Relaxing these dependencies and using general departure dates and flight durations from literature led to even poorer predictions (not shown).

Blouin et al. (1999) advised against using harnesses on geese, because the additional weight and influence on their aerodynamics distorts the birds' movement. Because of the pair bonds, it is likely that males are slowed down by their females that have to carry extra fat load for breeding, rather than by aerodynamic or weight impacts of the transmitters. Another general problem is that tags often fail. Indeed, we did have a lot of tag failures, but this is not uncommon and could often be attributed to geese destroying the antenna and harness (Malecki et al. 2011), technical failures and hunting. Furthermore, our data showed good spatial and temporal agreement with ring recovery data, indicating that the selected individuals are sufficiently representative for the studied population. The spatial agreement was however not perfect; more rings had been recovered in the south-east of the species' range. This may purely be bias due to extremely high hunting pressure and higher willingness to report rings in those regions.

Other factors may also play a role during the geese's migration, such as wind direction, wind speed, air pressure and flight altitude (Shamoun-Baranes et al. 2010). In this study we did not take these proximate factors into account, but they may play an important role on shorter time frames than the green wave, and may for instance determine the exact moment of departure from a stopover site (Beekman et al. 2002). Additionally, white-fronted geese may delay their migration timing due to hunting, as this species is heavily hunted in Eastern Europe (Kruckenberg et al. 2008a), especially on their southern routes.

Concluding, the green wave hypothesis seems to be a valid hypothesis for explaining the timing of spring migration in European greater white-fronted geese. The geese closely followed peaks in GDD jerk, which in turn seems closely related to the very onset of spring, or the front of the green wave. These results suggest that white-fronted geese are essentially dependent on feeding during their spring migration which has important implications for its conservation, especially in light of recent declines in the species' breeding success (Koffijberg 2010). Furthermore, geese may be expected to face changes in the timing of their migration as shifts in spring phenology are expected to occur in the coming century (Berteaux et al. 2004).

Acknowledgements - First of all we would like to thank the Vogulschutz-Komitee e.V. (VsK Hamburg), Alterra Wageningen-UR and the Dutch Society of Goosecatchers for the financial and technical support in catching and tracking the geese. A. V. Kondratyev was of great help defining and discussing the breeding sites and breeding status of the different birds. H. J. Stuiver helped out on the GIS work. We thank H. van der Jeugd (Dutch Centre for Avian Migration and Demography) for kindly providing us with the data on ring recoveries. We would like to thank B. Hoye for very helpful comments on the manuscript. AK is supported by the Strategic Fund of the KNAW, granted to J. van de Koppel, M. Naguib and BAN. This is publication (5088) of the Netherlands Institute of Ecology (NIOO-KNAW).

\section{References}

Bauer, S. et al. 2011. Cues and decision rules in animal migration. - In: Milner-Gulland, E. J. et al. (eds), Animal migration: a synthesis. Oxford Univ. Press, pp. 68-87.

Beekman, J. H. et al. 2002. Skipping swans: fuelling rates and wind conditions determine differential use of migratory stopover sites of Bewick's swans Cygnus bewickii. - Ardea 90: $437-460$.

Berteaux, D. et al. 2004. Keeping pace with fast climate change: can Arctic life count on evolution? - Integr. Comp. Biol. 44: $140-151$

Black, J. M. et al. 2007. Wild goose dilemmas. - Branta Press.

Blouin, F. et al. 1999. The use of satellite telemetry to track greater snow geese. - J. Field Ornithol. 70: 187-199.

Bos, D. et al. 2005. The relative importance of food biomass and quality for patch and habitat choice in Brent geese Branta bernicla. - Ardea 93: 5-16.

Botta, A. et al. 2000. A global prognostic scheme of leaf onset using satellite data. - Global Change Biol. 6: 709-725.

Budeau, D. A. et al. 1991. Energy dynamics, foraging ecology, and behavior of prenesting greater white-fronted geese. - J. Wildlife Manage. 55: 556-563.

Drent, R. H. et al. 1978. Balancing the energy budgets of arcticbreeding geese throughout the annual cycle: a progress report. - Verhandl. Ornithol. Gesellschaft Bayern 23: 239-264. 
Drent, R. et al. 2003. Pay-offs and penalties of competing migratory schedules. - Oikos 103: 274-292.

Drent, R. H. et al. 2006. Migratory connectivity in Arctic geese: looking for the weakest link. - J. Ornithol. 147: 52-52.

Duriez, O. et al. 2009. What decision rules might pink-footed geese use to depart on migration? An individual-based model. - Behav. Ecol. 20: 560-569.

Ely, C. R. et al. 2007. Reproductive strategies of northern geese. Why wait? - Auk 124: 594-605.

Fitzjarrald, D. R. et al. 2001. Climatic consequences of leaf presence in the eastern United States. - J. Climate 14: 598-614.

Fox, A. D. et al. 1991. Snow-patch foraging by pink-footed geese Anser brachyrhynchus in south Iceland. - Holarct. Ecol. 14: 81-84.

Hamel, S. et al. 2009. Spring normalized difference vegetation index (NDVI) predicts annual variation in timing of peak faecal crude protein in mountain ungulates. - J. Appl. Ecol. 46: 582-589.

Haylock, M. R. et al. 2008. A European daily high-resolution gridded data set of surface temperature and precipitation for 1950-2006. - J. Geophys. Res. Atmospheres 113: D20119.

Holdo, R. M. et al. 2009. Opposing rainfall and plant nutritional gradients best explain the wildebeest migration in the Serengeti. - Am. Nat. 173: 431-445.

Hüppop, O. and Hüppop, K. 2003. North Atlantic Oscillation and timing of spring migration in birds. - Proc. R. Soc. Lond. B 270: 233-240.

Kobayashi, K. and Salam, M. U. 2000. Comparing simulated and measured values using mean squared deviation and its components. - Agron. J. 92: 345-352.

Koffijberg, K. 2010. Breeding success amongst greater whitefronted geese in 2009/10 - a progress report. - Goose Bull. Nov. 2010: 32-34.

Krechmar, A. V. and Kondratyev, A. V. 2006. Waterfowl birds of northeast Asia. - Academic Science, Far East Branch.

Kruckenberg, H. 2003. Muster der Raumnutzung markierter Blessgänse (Anser albifrons albifrons) in West- und Mitteleuropa unter Berücksichtigung sozialer Aspekte. - Univ. Osnabrück.

Kruckenberg, H. and Borbach-Jaene, J. 2004. How traditional are roosting greylags? Sitefidelity of colour-marked Nordic greylag geese Anser anser on spring migration. - J. Ornithol. 145: $117-122$.

Kruckenberg, H. et al. 2008a. White-fronted goose flyway population status. - Angew. Feldbiol. 2: 1: 77.

Kruckenberg, H. et al. 2008b. Satellite tracking of greater whitefronted geese Anser albifrons during spring migration 2006 preliminary results. - Vogelwelt 129: 338-342.

Lantinga, E. A. 1985. Productivity of grasslands under continuous and rational grazing. - Univ. of Wageningen, the Netherlands.
Lappalainen, H. K. et al. 2008. Long-term trends in spring phenology in a boreal forest in central Finland. - Boreal Environ. Res. 13: 303-318.

Malecki, R. A. et al. 2011. Harnessing those pesky Anser species. - Goose Bull. 12: 19-24.

Marra, P. P. et al. 2005. The influence of climate on the timing and rate of spring bird migration. - Oecologia 142: 307-315.

Mueller, T. et al. 2008. In search of forage: predicting dynamic habitats of Mongolian gazelles using satellite-based estimates of vegetation productivity. - J. Appl. Ecol. 45: 649-658.

Owen, M. 1980. Wild geese of the world. - Batsford.

Reynolds, J. M. 1981. The distribution of mean annual temperatures in the Antarctic Peninsula. - Br. Antarct. Surv. Bull. 54: 123-133.

Sawyer, H. and Kauffman, M. J. 2011. Stopover ecology of a migratory ungulate. - J. Anim. Ecol. 80: 1078-1087.

Schwartz, M. D. 1998. Green-wave phenology. - Nature 394: 839-840.

Schwartz, M. D. et al. 2006. Onset of spring starting earlier across the Northern Hemisphere. - Global Change Biol. 12: 343-351.

Shamoun-Baranes, J. et al. 2010. Integrating meteorology into research on migration. - Integr. Compar. Biol. 50: 280-292.

Sherrill-Mix, S. A. et al. 2008. Migration cues and timing in leatherback sea turtles. - Behav. Ecol. 19: 231-236.

Spaans, B. et al. 1999. Cost of incubation in a greater white-fronted goose. - Waterbirds 22: 151-155.

Stahl, J. et al. 2006. Subtle interplay of competitions and facilitation among small herbivores in coastal grasslands. - Funct. Ecol. 20: 908-915.

Suzuki, R. et al. 2003. West-east contrast of phenology and climate in northern Asia revealed using a remotely sensed vegetation index. - Int. J. Biometeorol. 47: 126-138.

Tombre, I. M. et al. 2008. The onset of spring and timing of migration in two arctic nesting goose populations: the pink-footed goose Anser bachyrhynchus and the barnacle goose Branta leucopsis. - J. Avian Biol. 39: 691-703.

van der Graaf, S. A. J. et al. 2006. Surfing on a green wave - how plant growth drives spring migration in the barnacle goose Branta leucopsis. - Ardea 94: 567-577.

van Eerden, M. R. et al. 2005. Connecting seas: western Palaearctic continental flyway for water birds in the perspective of changing land use and climate. - Global Change Biol. 11: 894-908.

van Liere, D. W. et al. 2009. Feeding preferences in greylag geese and the effect of activated charcoal. - J. Wildlife Manage. 73: 924-931.

Wang, J. Y. 1960. A critique of the heat unit approach to plantresponse studies. - Ecology 41: 785-790. 


\section{Appendix 1}

\section{Comparison of RMSD values}

In the following we provide a table of RMSD values of the complete set of models that have been tested to predict the timing of arrivals during spring migration. From Table A1 it becomes clear that the GDD jerk does not only generally provide a good prediction of spring migration timing of white-fronted geese, it also seems to distinguish non-breeders, failed breeders and successful breeders. Predictions from green wave related variables such as the GDD, GDD jerk and day of snow melt revealed better or worse RMSD values in relation to breeding status. Such a pattern does not appear for alternative predictors, like photoperiod or latitude.

\section{Appendix 2}

\section{Comparison of onset of spring growth defined by NDVI vs GDD jerk}

In order to evaluate the method developed in this study, the GDD jerk, we compared the timing of the onset of spring growth as defined using NDVI data (Suzuki et al. 2003) with the times of maximum GDD jerk. This was carried out over a large region in northern Asia. We used the same weather stations that were reference points in the study by Suzuki et al. (2003) and tried to use weather data of one weather station per degree longitude (data provided by R. Suzuki). In total, this added up to 76 weather stations in the region of $30-135^{\circ} \mathrm{E}$ and $45-50^{\circ} \mathrm{N}$. We derived daily average temperatures, GDD sigmoid curves and eventually times of GDD jerk maxima (Fig. A1).

It becomes apparent that the GDD jerk generally predicts the onset of spring one to two weeks earlier than NDVI. However, since NDVI is a weekly measure, this divergence lies in the order of data accuracy. Thus, the GDD jerk seems a valid measure for predicting the onset of spring growth. Because the GDD jerk always predicts an earlier onset of growth then NDVI, we conclude that it represents the very start of growth, rather than start of greenness.

When going from west to east the difference between predictions by NDVI and GDD jerk increases. This might be an indicator of the influence of snow on spring growth. Many plants already start growing under the snow. Additionally, the GDD jerk nicely confirms the existence of the green wave, i.e. an eastward delay of the onset of spring.

Table A1. Complete table of RMSD values (in days) of all models used in the study for the set of tracked birds. Measures classified as a poor predictor are highlighted in italic, bold indicates good fits and normal style numbers are moderate fits. The order of bird IDs follows breeding status, birds 79689 and 79696 definitely being non-breeders and 72413 and 79694 were observed to be successful breeders.

\begin{tabular}{|c|c|c|c|c|c|}
\hline Bird ID & GDD $180^{\circ} \mathrm{C}$ & GDD jerk & Snow cover & Photoperiod & Latitude \\
\hline 79689 & 30.94 & 18.35 & 12.81 & 16.16 & 14.60 \\
\hline 79696 & 24.42 & 16.38 & 18.26 & 8.02 & 18.00 \\
\hline 62350 & 9.71 & 16.45 & 15.17 & 7.44 & 32.09 \\
\hline 72364 & 28.47 & 15.26 & 7.91 & 24.56 & 23.63 \\
\hline 72416 & 33.52 & 11.97 & 22.63 & 30.52 & 18.41 \\
\hline 73052 & 21.89 & 10.75 & 17.11 & 22.08 & 19.12 \\
\hline 72417 & 34.19 & 10.11 & 18.12 & 9.14 & 18.99 \\
\hline 73053 & 21.38 & 8.89 & 12.95 & 26.88 & 13.29 \\
\hline 79695 & 28.41 & 13.53 & 19.10 & 7.85 & 12.85 \\
\hline 73054 & 18.50 & 10.91 & 16.17 & 15.44 & 13.33 \\
\hline 79698 & 10.88 & 7.73 & 11.97 & 22.61 & 17.39 \\
\hline 72413 & 15.97 & 13.96 & 14.82 & 12.98 & 10.79 \\
\hline 79694 & 20.81 & 13.49 & 19.34 & 36.03 & 19.72 \\
\hline Overall & 23.90 & 13.63 & 15.24 & 19.59 & 18.54 \\
\hline
\end{tabular}

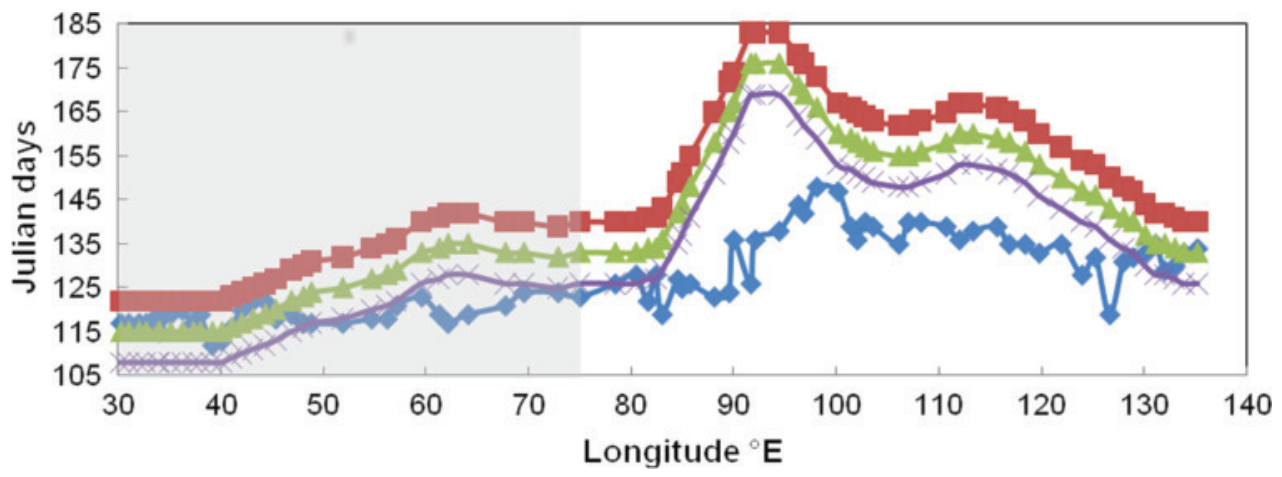

Figure A1. Onset of spring growth as defined by GDD jerk maxima vs NDVI data derived from Fig. 5A in Suzuki et al. (2003). The blue line with diamonds represents the time of maximal GDD jerk, the red line with squares indicates the predicted onset of spring growth using NDVI data, the green line with triangles shows the same data minus one week and, lastly, the purple line with crosses is the predicted starting date of spring growth using NDVI data minus two weeks. Indicated in gray is the area over which white-fronted geese migrate. 